\title{
CONTRIBUTIONS OF THE RESEARCH LINE ON LITERACY AND DIGITAL INCLUSION OF WOMEN: OVERCOMING DIGITAL DIVIDES AND OBTAINING REAL BENEFITS IN THEIR DAILY LIVES
}

\author{
Rocío Jiménez Cortés, Universidad de Sevilla, Spain
}

\section{Abstract}

This research follows a trajectory of work in the field of women's studies and learning with digital technologies. The research is undertaken by the DIME HUM 833 research group from University of Seville (Spain). Extensive research projects have basically focused on: (a) characterize the processes of digital inclusion and know how women (with different profiles professionals, entrepreneurs, unemployed, students ...) learn with technologies and overcome digital divides (MAIA Project), (b) to value the processes of participation and learning in social networks and their influence on the subjective and emotional well-being of women (RURAL WOMEN Project). A third research in process is presented on the line (ALCMENA Project). The aim of this project is (c) describe the situation of middle-aged and older women in the Andalusian Digital Society and learn about their experiences with digital technologies.

Mixed-type research has been developed from a survey studies and qualitative studies based on techno-autobiographical interviews and thinking aloud protocols. The final sample was made up of 1340 women for the MAIA Project and specifically 478 in rural areas for the RURAL WOMEN Project.

The results show a moderate degree of digital inclusion of women. The results point to the research offers a detailed knowledge of the role that current digital technologies are playing in the lives of a wide diversity of women. The results show different learning ecologies from the women with different profiles. The results are shown in detail in the book Jiménez-Cortés et al. (2016).

At the same time, the research shows that participation in democratic processes online has the potential to improve the quality of life of women and gives them greater control over their lives and satisfaction. This knowledge allows women to prepare for an active and full digital citizenship, which brings them well- 
Jiménez Cortés, $R$.

Contributions of the Research Line on Literacy and Digital Inclusion of Women: Overcoming Digital Divides and Obtaining Real Benefits in their Daily Lives

being. The results are shown in detail in other papers (Jiménez-Cortés, 2015; 2016).

The expected results of the ALCMENA Project will show processes of digital empowerment and strategies of middle-aged and older women that serve as a reference to guide the actions of interested social agents and institutions.

Keywords: women's studies, digital literacy, learning, social media, well-being, digital divide

\section{Introduction and justification of the research line}

Digital literacy constitutes one of the main political lines of action in Europe and Spain, mainly due to its repercussions on the digital economy. It is a key objective of the Digital Agendas for Europe and Spain. The National Plan for Digital Inclusion and Employability incorporates literacy as its main axis. The digital literacy is defined as the development of digital skills by the most vulnerable groups such as women (Jiménez-Cortés, 2016). The promotion of lifelong learning to develop ICT skills result a key matter of social justice for overcoming digital inequalities. These inequities have been documented by national (Menéndez, 2012) and international research (van Dijk, 2005).

The telecentre networks such as Guadalinfo in Andalusia (Spain) and their educational initiatives for digital literacy are a clear example of the political will to bring ICTs to different sectors of the citizenry. The finality is to break the first digital divide (related to with access resources to digital technologies (devices and connectivity) and the second digital divide (linked to skills and use (Castaño, Martín, Vázquez, \& Martínez, 2009).

Current international research points to the existence of a larger number of digital divides overlapping (Hargittai \& Walekjo, 2008; Hoffmann, Lutz, \& Meckel, 2015; Jiménez-Cortés, Vega-Caro, \& Vico-Bosch, 2016; Jiménez-Cortés, Ruiz, \& Vega, 2016). This knowledge draws a complex landscape for the design of effective educational actions capable of mitigating digital inequalities. However, these political, social and economic purposes of using ICTs must necessarily translate into real benefits for women. These benefits, that can be derived from digital literacy processes, are of a very different nature. For example is a benefit for women the exercise of active digital citizenship (Jiménez-Cortés, 2016) or the implementation of online business ideas, the quality of life (García-Pérez, Jiménez-Cortés, \& Rodríguez, 2013) and well-being (Jiménez-Cortés, 2015; 2016). This implies two great challenges for educational research: (a) to review and rethink the concept of digital literacy from the real experience of women. On the same lines, political strategies must be sensitive to new ways of learning about ICT, (b) it is crucial to identify the real benefits, that is, 
Jiménez Cortés, $R$.

Contributions of the Research Line on Literacy and Digital Inclusion of Women: Overcoming Digital Divides and Obtaining Real Benefits in their Daily Lives

tangible results that the digital inclusion processes are contributing to women in their daily lives.

\section{Research line objectives}

The research line on digital literacy and digital inclusion for women has been developing intensively in the last six years for cover different objectives, in relation with the challenges:

- Characterize the processes of digital inclusion and know how women of different profiles (professionals, entrepreneurs, unemployed, students ...) learn with technologies and overcome digital divides. This is the main purpose of MAIA project. Women as Weavers of Social Networks: Relational Strategies and Digital Inclusion State Plan 2013-2016 Excellence - R\&D Projects (Reference: EDU201345134-P).

- To value the processes of participation and learning in social networks due to their influence on the subjective and emotional well-being of women. Under the project Relational Quality, Digital Immersion and Social Well-being from a Gender Perspective. An Application of Online Social Networks in Rural Andalusian Women. Projects of Excellence of the Junta de Andalucía (Reference: P10-SEJ5801).

- Describe the situation of middle-aged and older women in the Andalusian Digital Society and learn about their experiences with digital technologies (Project presented at " $\mathrm{R}+\mathrm{D}+\mathrm{i}$ projects" universities and public research entities (BOJA No. 203, 10/18/2018) Research Projects Oriented to the Challenges of the Andalusian Society).

\section{Research methodology}

The methodological design is a mixed research. Thus, a survey-type descriptive method is combined with a more comprehensive, ethnographic, phenomenological methodological approach, which delves into the thoughts and experiences of women using interviews, think-aloud protocols and micro-audio-stories.

\section{Sampling procedures and participants}

Different samples are used for research according to objectives. The final sample was made up of 1340 women for the MAIA Project (women residing in Andalusia and Extremadura), selected from a sampling by quotas considering the employment situation (employed, unemployed, students, housewives and retired) and the age of the women (20 to 25 years, 26-34 years, 35-44 years, 45-54 years, 55-64 years, more than 65 years). Which represents an appropriate size for a sample error rate below 5\% (with a confidence level of $95.5 \%$ and $\mathrm{p}=\mathrm{q}=50 \%)$. 
Jiménez Cortés, $R$.

Contributions of the Research Line on Literacy and Digital Inclusion of Women: Overcoming Digital Divides and Obtaining Real Benefits in their Daily Lives

The selection of women from rural areas (who use digital social networks) was carried out with a sample stratified by quotas, taking four age strata (18-25, 26-39, 40-54 and 55-65) and three strata depending on educational levels (no education/compulsory education not finished, compulsory education completed and university education) in the province of Seville. Which represents an appropriate size for a sample error rate below 5\% (with a confidence level of $95.5 \%$ and $\mathrm{p}=\mathrm{q}=50 \%$ ).

To deepen on a qualitative level, we selected a total of 30 women. A theoretical snowball sampling is followed to locate women who, meeting the established sampling inclusion criteria, have the maximum variability of profiles.

For de Alcmena Project the sample size is expected to be made up of 400 Andalusian women over 50 years of age with a sampling error of the global data close to $\pm 5 \%$ with a confidence level of $95 \%$ and $p=q=0.5$. It is planned to carry out this selection of women through an incidental sampling by quotas according to age groups (middle age, between 50-65 years and older, between 65-90 years).

For qualitative phase the sample size is expected to be 40 women following a theoretical snowball sampling and a sampling of discrepant cases. The use of a tablet or iPad will be considered as the main inclusion criterion, since current research shows that it is the device that makes a difference in the access and use that women make of the internet (Lee \& Coughlin, 2015).

\section{Data collection instruments}

Quantitative data collection is carried out through the C.A.W.I. (self-administered interview by online computer) without the use of online panels and printed questionnaires are also used that collect different scales and measures, including:

- Scale on digital inclusion based in Bradbrook and Fisher (2004) and Helsper (2008). She obtains a Cronbach's alpha coefficient of .829 .

- Scale on literacy and digital competence (Internet skills) based in van Deursen, Helsper, and Eynon (2014) and on technical reports from the UK government. She obtains a Cronbach's alpha coefficient of .871.

- Informal learning scale in networks (MAIA scale) (Jiménez-Cortés, 2019) based in Heo and Lee (2013) and Fenwick and Tennant (2004). She obtains a Cronbach's alpha coefficient of .948 .

- Emotional well-being scale. This scale is based on an osgood-type semantic differential on a graphic scale from 0 to 10 , the composite reliability is $\rho c=.9759$. 
Jiménez Cortés, $R$.

Contributions of the Research Line on Literacy and Digital Inclusion of Women: Overcoming Digital Divides and Obtaining Real Benefits in their Daily Lives

Qualitative data collection is done using:

- Technological-autobiographical interviews include questions such as "When you have needed to go online to learn something quickly, where do you usually go (to web pages, to YouTube, to networks...)? What are the things you have been interested in learning about at certain times?

- Thinking aloud protocols for women to collect information about their Internet connections, relating aspects such as, what has led them to connect, where they are and from where they access the Internet in the form of micro-audio-stories , pages you are browsing and why, difficulties,...

\section{Analysis procedures}

Exploratory analysis techniques are realized with the software SPSS v.23. The analysis uses the Partial Least Squares (PLS) techniques, designed for predictive analyses in which the problems explored are complex (Chin, Marcolin, \& Newsted, 2003) and theoretical knowledge has not been consolidated (Barclay, Higgins, \& Thompson, 1995), as is the case with well-being on digital social networks (Jiménez-Cortés, 2015). To do this, we used the Smart PLS 2.0 programme (Ringle, Wende, \& Will, 2005).

For qualitative data, analytical techniques based on grounded theory, discourse analysis and thematic analysis using the ATLAS ti software. v. 6.2.

\section{Ethical implications of the research}

The research incorporates informed consents that require acceptance by women before proceeding to their participation. The collection of information is carried out under a confidentiality declaration by the people involved in the data collection and the analytical treatment procedure of the data is anonymized.

\section{Main results and value of contributions}

In relation with the first objective and the MAIA Project, the study of the digital inclusion of women, shows that $48.8 \%$, (640 women) presents a moderate degree of digital inclusion. The advanced degree of digital inclusion is reached only by $36.1 \%$ of women. The study of the factors of digital inclusion (connectivity, confidence, participation) in isolation show the aspects in which women present more barriers to an effective use the digital technologies. We observe that $44.6 \%$ (490 women) show little digital confidence. The qualitative analysis reveals new explanations for digital inclusion. The women overcoming of barriers related to technical aspects and programming languages, overcome beliefs and emotional resistance to the online life, linked to feelings of shame, fear and lack of confidence. 
Jiménez Cortés, $R$.

Contributions of the Research Line on Literacy and Digital Inclusion of Women: Overcoming Digital Divides and Obtaining Real Benefits in their Daily Lives

The characterization of these digital inclusion processes has been the key contribution of this research, cataloguing and relating motives for use (Jiménez-Cortés et al. 2015), barriers and ways of overcoming digital divides. The relevance of the informal support network and the effects of the attitudes and behaviours of family, friends and / or the community explain the differences in literacy and digital inclusion. This result is key to changing the approach the politics strategies on digital literacy very focused on individual development of ICT skills that does not consider the context in which women are immersed. This new approach involves reconceptualising "digital literacy" from a more holistic point of view. It is essential to assess digital literacy proposals from a new approach more centred on the characteristics of the context and informal support networks of each woman.

At the same time, the research offers a detailed knowledge of the role that current digital technologies are playing in the lives of a wide diversity of women. The results trace different characteristic learning ecologies of women with different profiles. This knowledge helps to propose and design personalized learning routes for profiles and sensitive to their ways of learning (Jiménez-Cortés et al., 2017). This knowledge has a special impact on the content of orientation and professional development of the students, for example.

In relation with the second objective, the results obtained show the importance of social networks for the lives of women. And it is that, participation and relationships maintained in digital social networks positively influence the subjective well-being of women. The confirmatory empirical models obtained show that identity consistency has a direct effect on life satisfaction with networks. The informal learning processes (participation and relationships in virtual social networks) influence to identity (Jiménez-Cortés, 2015). The training initiatives, publics or privates, must incorporate the use of social networks and reorient the pedagogical design of these spaces in this sense. This approach on the technopedagogical design of virtual learning environments is important for women to obtain this personal benefit.

At the same time, the research shows that participation in democratic processes online has the potential to improve the quality of life of women and gives them greater control over their lives. This knowledge allows women to prepare for an active and full digital citizenship (Jiménez-Cortés, 2016).

The main value of these contributions is that they help guide public investment in digital literacy by adapting political strategies to women's profiles and also improve the technopedagogical designs of training initiatives by incorporating social networks that respect the 
Jiménez Cortés, $R$.

Contributions of the Research Line on Literacy and Digital Inclusion of Women: Overcoming Digital Divides and Obtaining Real Benefits in their Daily Lives

identity of women, knowing that there are concrete digital practices on the network that have real benefits, such as well-being or the exercise of active and full digital citizenship.

We consider that the educational, political, social and economic strategies for the use of ICT, they must necessarily translate into real benefits for women.

\section{Future research line}

The ALCMENA Project arises with the purpose of describing the situation of women from middle-aged and older in the Andalusian Digital Society and learn about their experiences with digital technologies. To do this, it will investigate their literacy and digital inclusion, how exercise citizenship and digital empowerment (activities on the Internet and use they make of digital services), the myths they assume (beliefs and attitudes towards technologies digital) and the real benefits and quality of life that they report. The experiences of these women and their perceptions will help understand the ways they learn with technologies and how they bridge digital gaps. In short, we try to value your knowledge and experiences in order to offer strategies for social innovation especially aimed at this group and capable of promoting their inclusion in a society digitized as is the Andalusian.

Current research on digital living, show the relevance of the incorporation of certain sectors of the population to the use of ICT (Novo-Corti, Varela-Candamio, \& GarcíaÁlvarez, 2014; Vergés, 2012).The older women require awareness and confidence towards the use of ICT, quality access to the Internet and digital skills that allow them to meet their health, training, entertainment, management needs with the public administration and the use of digital services. The ALCMENA Project promotes innovative proposals for the Andalusian Digital Society.

This project tries to deepen aspects such as literacy and digital inclusion, the exercise of digital citizenship and the processes of empowerment of women, myths, beliefs and attitudes towards ICTs and the real benefits they obtain and the quality of life. These study dimensions will be offering a clear understanding of the situation of Andalusian middleaged and elderly women in this digitized society.

\section{References}

Barclay, D., Higgins, C., \& Thompson, R. (1995). The Partial Least Squares (PLS)

Approach to causal modelling: Personal computer adoption and use as an illustration. Technology Studies, 2, 285-309.

Bradbrook, G., \& Fisher, J. (2004). Digital Equality: Reviewing Digital Inclusion Activity and Mapping the Way. Forwards. London: Citizens Online. 
Jiménez Cortés, $R$.

Contributions of the Research Line on Literacy and Digital Inclusion of Women: Overcoming Digital Divides and Obtaining Real Benefits in their Daily Lives

Castaño, C., Martín, J., \& Vázquez, S. (2008). La e-inclusión y el bienestar social: una perspectiva de género. Economía Industrial, 367, 139-152

Chin, W. W., Marcolin, B. L., \& Newsted, P. R. (2003). A partial least square latent variable modeling approach for measuring interaction effects: Results from a Monte Carlo simulation study and an electronic mail emotion/ adoption study. Information Systems Research, 14, 189-217. doi:10.1287/isre.14.2.189.16018

Cotten, S. R. (2009). Using ICTs to enhance quality of life among older adults: Preliminary results from a randomized controlled trial. Paper presented at the Annual Meeting of the Gerontological Society of America.

van Deursen, A. J. A. M., Helsper, E., \& Eynon, R. (2014). Measuring Digital skills. From Digital Skills to Tangible Outcomes project report. London: University of Twente.

van Dijk, J. (2005). The Deepening Divide Inequality in the Information Society. London: Sage Publications.

Fenwick, T., \& Tennant, M. (2004). Understanding adult learners. In G. Foley (Ed.), Dimensions of adult Learning: Adult education and training in a global era adult education and training (pp. 55-73). Sydney, Australia: Allen \& Unwin

Hargittai, E., \& Walejko, G. (2008). The participation divide: Content creation and sharing in the digital age. Information, Communication \& Society, 11(2), 239-256. doi:10.1080/13691180801946150

Helsper, E. (2008). Digital inclusion: an analysis of social disadvantage and the information society. London: Department for Communities and Local Government.

Heo, G. M., \& Lee, R. (2013). Blogs and social network sites as activity systems: Exploring adult informal learning process through Activity Theory framework. Educational Technology \& Society, 16, 133-145

Hoffmann, Ch. P., Lutz Ch., \& Meckel, M. (2015): Content creation on the Internet: a social cognitive perspective on the participation divide. Information, Communication \& Society, 18(6), 696-716. doi:10.1080/1369118X.2014.991343

Jiménez-Cortés, R. (2015). Influencia de los procesos de aprendizaje informal en el bienestar subjetivo de las mujeres de zonas rurales. Cultura y Educación, 27(2), 407439

Jimenez-Cortés, R. (2016). Ciudadanía digital y bienestar de las mujeres rurales en las redes sociales. RELATEC, 15(2). 
Jiménez Cortés, $R$.

Contributions of the Research Line on Literacy and Digital Inclusion of Women: Overcoming Digital Divides and Obtaining Real Benefits in their Daily Lives

Jiménez-Cortés, R. (2019). Aprendizaje de las mujeres en las redes sociales: validación de la escala MAIA con PLS. Revista de Investigación Educativa, 37(2), 431-449.

http://dx.doi.org/10.6018/rie.37.2.325721

Jiménez-Cortés, R., Rebollo-Catalán, M. A., García-Pérez, R., \& Buzón-García, O. (2015). Social network user motivation: An analysis of rural women's profiles. RELIEVE, 21(1), art. 2.

Jiménez-Cortés, R. Rebollo, A., \& García, R. (Eds.) (2016). Aprendizaje con TIC para la inclusión digital. Las mujeres como tejedoras de las redes sociales. Madrid: Síntesis

Jiménez-Cortés, R., Ruiz, E., \& Vega, L. (2016). La inclusión digital de las mujeres o cómo superar las brechas digitales. In R. Jiménez-Cortés, A. Rebollo, \& R. García (Eds.), Aprendizaje con TIC para la inclusión digital. Las mujeres como tejedoras de las redes sociales (pp-69-80). Madrid: Síntesis.

Jiménez-Cortés, R., Vega-Caro, L., \& Vico-Bosch, A. (2016). Habilidades en Internet de mujeres estudiantes y su relación con la inclusión digital: Nuevas brechas digitales. Education in the Knowledge Society (EKS), 17(3), 29-48. doi:10.14201/eks20161732948

Jiménez-Cortés, R., Vico-Bosch, A., \& Rebollo-Catalán, A. (2017). Female university student's ICT learning strategies and their influence on digital competence. International Journal of Educational Technology in Higher Education, 14, 1-12. https://doi.org/10.1186/s41239-017-0040-7

Lee, C., \& Coughlin, J. F. (2015). Adoption of technology by older adults: an integrated approach to identify determinants and barriers. Magazine of Management of Product Innovation, 32(5), 747-759.

Lin, C., Tang, W., \& Kuo, F. (2012). Mommy Wants to Learn the Computer: How Middle Aged and Elderly Women in Taiwan Learn ICT Through Social Support. Adult Education Quarterly, 62(1), 73-90. doi:10.1177/0741713610392760

Novo-Corti, I., Varela-Candamio, L., \& García-Álvarez, T. (2014). Breaking the walls of social exclusion of women rural by means of ICTs: The case of "digital divides" in Galician. Computers in Human Behavior, 30, 497-507. doi:10.1016/j.chb.2013.06.017

Ringle, C. M., Wende, S., \& Will, A. (2005). Smart PLS 2.0 (M3) Beta.

Vergés, N. (2012). De la exclusión a la autoinclusión de las mujeres en las TIC. Motivaciones, posibilitadores y mecanismos de autoinclusión. Athenea Digital, 12(3), 129-150. 